\title{
Gold Coatings to Protect Chromium Alloys Against Nitridation
}

\author{
E. A. Brandes \\ Fulmer Research Institute, Stoke Poges, England
}

The development of chromium alloys for high temperature applications has been delayed by the lack of an effective treatment to prevent their embrittlement by nitrogen absorbed during exposure to hot gases. Nitrogen has no solubility in gold and thus it is feasible that a protective gold layer would prevent absorption of nitrogen into the underlying chromium. This has now been confirmed experimentally. The temperature range over which the coating can be used has also been extended by alloying the gold with palladium, thus raising the melting point of the coating. Tests in a simulated gas turbine have demonstrated the resistance of the coating to thermal fatigue at $1100^{\circ} \mathrm{C}$.

The history of the development of jet engines is closely integrated with that of turbine stator and rotor blade materials. Gas turbine engine efficiency increases with gas inlet temperature, and there is therefore a continuing demand for materials of high temperature strength and toughness combined with oxidation resistance for both turbine blades and nozzle guide vanes.

Initially, nickel-base super-alloys such as the Nimonic series were used and by use of casting processes and internal coating these alloys have been steadily developed to operate at higher temperatures, in fact at temperatures close to the melting point of the alloy.

Highly directionally solidified eutectics are now llowing the use of still higher temperatures, but even these materials are close to their upper temperature limits.

The general position of the candidate materials can be seen in the Larson-Miller plot of Figure 1, which shows the strength for rupture in 1000 hours plotted against temperature. Chromium-base alloys, especially those strengthened by dispersions of tantalum or niobium carbides, have a clear advantage at high temperatures, but unfortunately they have two major defects; they are brittle at room temperature and, secondly, prolonged heating at high temperatures in air causes them to absorb nitrogen which extends the brittleness range to higher temperatures. If this nitridation embrittlement could be overcome, the possibility of using these very creep resistant alloys in gas turbine engines would be much increased.

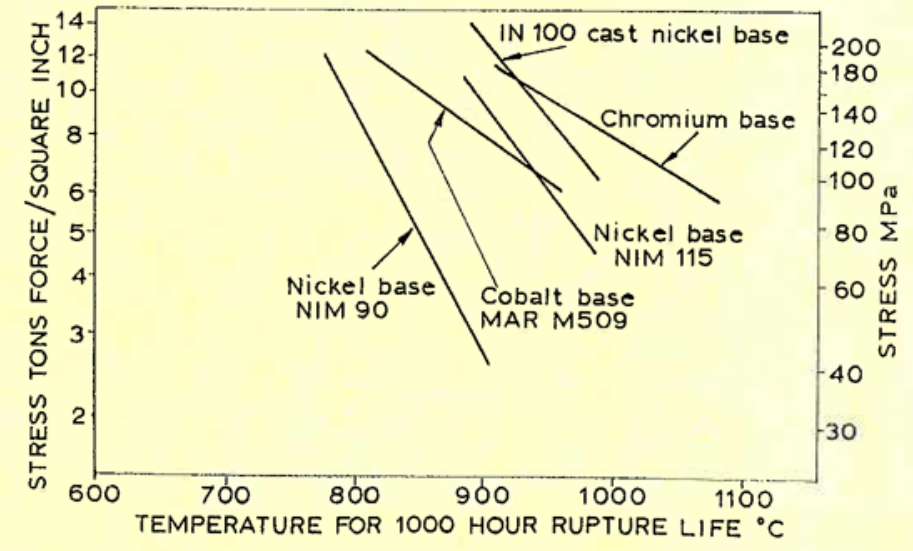

Fig. 1 Comparison of the creep properties of contending high temperature materials shown as the temperature for rupture after 1000 hours against stress. The superiority of chromium-base alloys above $1000^{\circ} \mathrm{C}$ is marked. Prevention of nitrogen embrittlement by the use of gold coatings might make chromium-base alloys practical engineering metals 


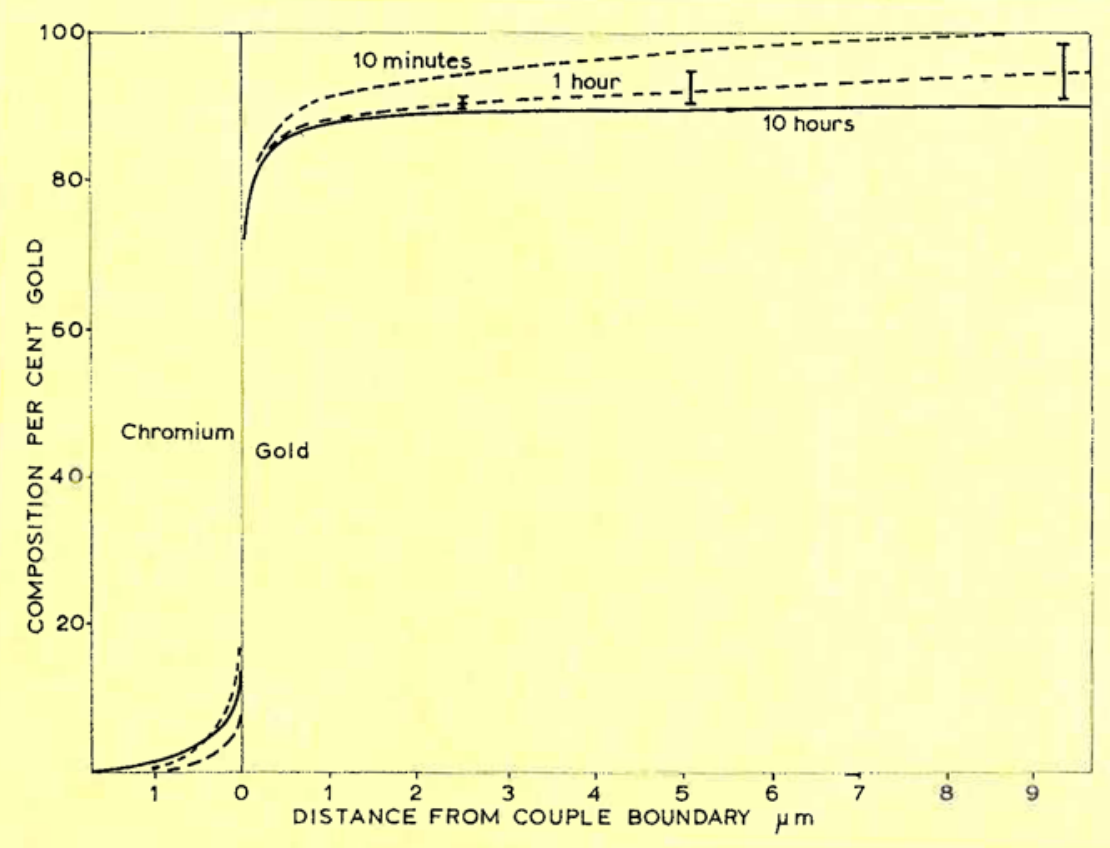

Fig. 2 The interdiffusion of gold and chromium at $850^{\circ} \mathrm{C}$ after various times, shown as concentration against distance from the original interface. Even after long periods at high temperatures the gold coating is not lost by diffusion

This research, carried out for the Chamber of Mines, has successfully shown how the second problem, nitrogen absorption, can be overcome.

\section{Protective Coating for Chromium Alloys}

For a coating to prevent the nitridation of chromium-base alloys, it must have the following properties:

Oxidation resistance

Integrity under operating conditions

Very good adhesion

Complete thermal shock resistance

Very low nitrogen permeability

Resistance to spalling or cracking
Gold has many properties which indicate its potential as a nitrogen barrier. First, it does not form a stable oxide and has negligible solubility for oxygen. Secondly, it has a very low solubility and diffuses very slowly into chromium so that the coating will not rapidly be lost, although the fact that chromium can dissolve in gold and thus diffuse to the surface might limit the effectiveness of the coating. The relative interdiffusions at high temperature are shown graphically in Figure 2. Thirdly, the ductility of gold suggests that a gold coating would have good resistance to thermal shock and spalling, and it has negligible solubility for nitrogen.

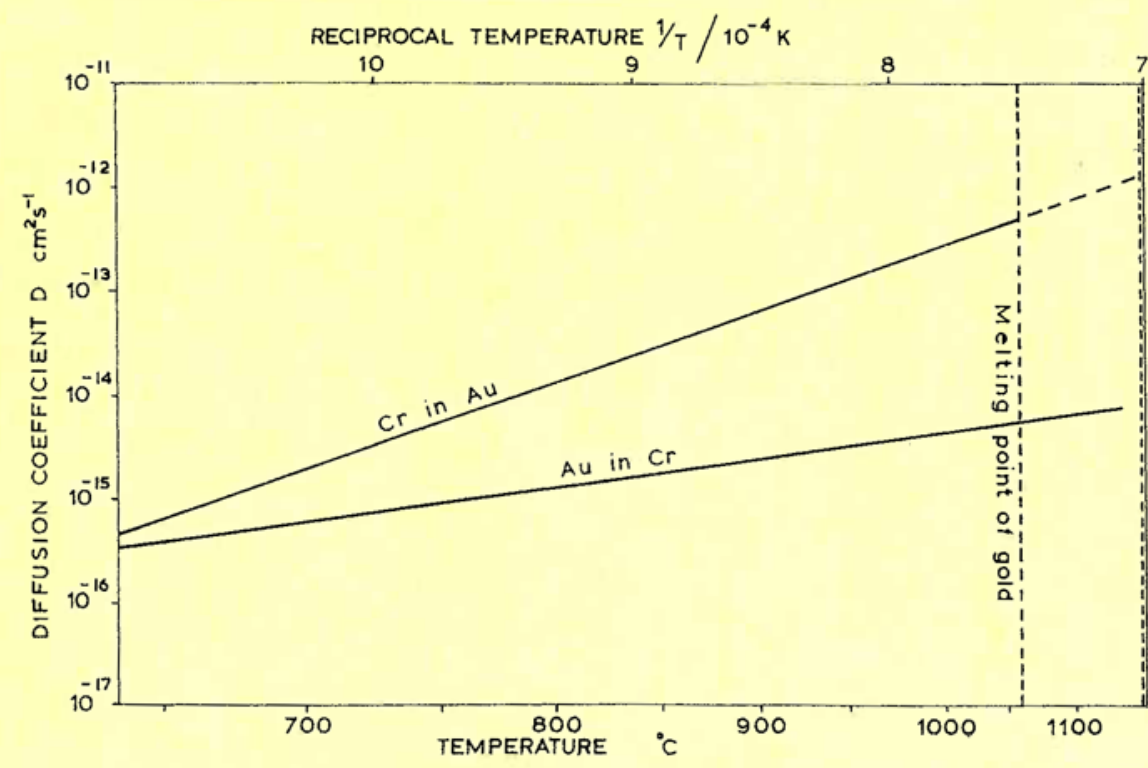

Fig. 3 The diffusion coefficients of gold in chromium and of ehromium in gold, shown as an Arrhenius plot of diffusion coefficient against the reciprocal of the absolute temperature 
The only doubts concern its adhesion to chromium, the extent to which chromium diffusion into the gold will affect its performance, and its low melting point, $1063^{\circ} \mathrm{C}$, though this will be raised to about $1100^{\circ} \mathrm{C}$ by chromium diffusion.

The gold plating bath found most effective was the Engelhard E55 solution, using a platinum anode. Pure chromium pieces coated by the technique finally developed were used for measurements of the diffusion of gold into chromium and of chromium in gold. A heat treatment step was found necessary to ensure good adhesion.

\section{Application of Gold Coatings}

Electroplating was the chosen method of application since by this means thin uniform coats could be deposited: other well-known processes for applying gold are equally feasible. A 15-step plating technique has been developed which provides excellent coatings. The system consists basically of:

(i) precleaning using a cathodic etching

(ii) activation, which is depassivation by cathodic treatment in hydrochloric acid

(iii) strike plating

(iv) heat treatment to effect adhesion of the strike coat

(v) plating to thickness

(vi) final re-heat treatment to effect full adhesion of main plate to the strike coat

\section{Diffusion Measurements}

Pure chromium strips, electroplated with gold as described, were sealed in fused quartz tubes under argon and heated for 10 minutes, 1 hour and 10 hours at each of the temperatures 700,850 and $1000^{\circ} \mathrm{C}$. The diffusion couples were then mounted and polished for examination on a Scanning Electron Microscope provided with an electron probe microanalyser. The gold and chromium compositional gradients were measured across the interface in each couple. Traces on each interface for gold and chromium were checked to ensure that they totalled 100 per cent, assuming that the trace height was proportional to the amount of each element.

Figure 2 shows the type of plot used. The concentration at distance $\mathrm{x} \mathrm{cm}$ from the interface after time, $t$ seconds, is given by

$$
C=\frac{C_{0}}{2}\left[1-e r f\left\{\frac{x}{2 \sqrt{\mathrm{Dt}}}\right\}\right]
$$

where $\mathrm{D}$ is the diffusion coefficient in $\mathrm{cm}^{2} / \mathrm{sec}$. The initial concentration $\mathrm{C}_{0}$ is unity, since to begin with pure gold and pure chromium formed the couple. Assuming that $\mathrm{D}$ varies as a function of the absolute temperature $T$ by the Arrhenius equation

$$
\mathrm{D}=\mathrm{D}_{\mathrm{o}} \exp (-\mathrm{Q} / \mathrm{RT})
$$

(where $Q$ is the enthalpy for diffusion of the relevant element and $R$ the gas constant), the reciprocal of the absolute temperature against $\mathrm{D}$ should be linear.

These plots of the diffusion of chromium in gold and for that of gold in chromium are shown in Figure 3, from which it can be seen that this is correct. From these plots the following results were obtained:

$$
\begin{aligned}
& \text { Diffusion of Chromium in Gold } D_{0}=1.8 \times 10^{-6} \mathrm{~cm}^{2} / \mathrm{s} \\
& Q=167 \pm 40 \mathrm{~kJ} / \mathrm{mole} \\
& \text { Diffusion of Gold in Chromium } D_{0}=2.2 \times 10^{-12} \mathrm{~cm}^{2} / \mathrm{s} \\
& Q=67 \pm 12 \mathrm{~kJ} / \mathrm{mole}
\end{aligned}
$$

These low diffusion rates show that the coating will not diffuse away rapidly into the chromium alloy. Slowly, chromium will diffuse into the coating steadily changing its composition towards higher chromium contents.

The diffusion results encouraged further development of gold coatings for chromium alloy protection.

\section{Protection Against Nitridation}

If a series of tensile tests is carried out on chromium alloys at increasing temperatures a sharp change is found from brittle to ductile failure. The temperature at which this takes place is the brittle-ductile transition temperature, and it is strongly influenced by nitrogen in that the transition temperature is raised as the nitrogen content increases.

It has already been stated that the embrittling effect of exposure to air at high operating temperature is one of the disadvantages of chromium-based metals. The protection which gold coatings can give to chromium or strong chromium-based alloys can be best estimated by exposing coated and uncoated samples to nitriding conditions and measuring

Table I

The Effect of Gold Protection on the Transition Temperature of Pure Chromium

\begin{tabular}{l|c|c|c}
\hline $\begin{array}{c}\text { Nitridation } \\
\text { Treatment }\end{array}$ & \multicolumn{2}{|c|}{ Transition Temperature ${ }^{\circ} \mathrm{C}$} & $\begin{array}{c}\text { Improvement } \\
\text { due to } \\
\text { Coating, }{ }^{\circ} \mathrm{C}\end{array}$ \\
\hline $\begin{array}{l}16 \text { hours in air at } \\
850^{\circ} \mathrm{C}\end{array}$ & 425 & 303 & 122 \\
\hline $\begin{array}{l}16 \text { hours in air at } \\
1000^{\circ} \mathrm{C}\end{array}$ & 385 & 340 & 45 \\
\hline $\begin{array}{l}5 \mathrm{cycles} \text { of } 20 \text { hours } \\
\text { heating in air at } \\
900^{\circ} \mathrm{C}\end{array}$ & 475 & 275 & 200 \\
\end{tabular}




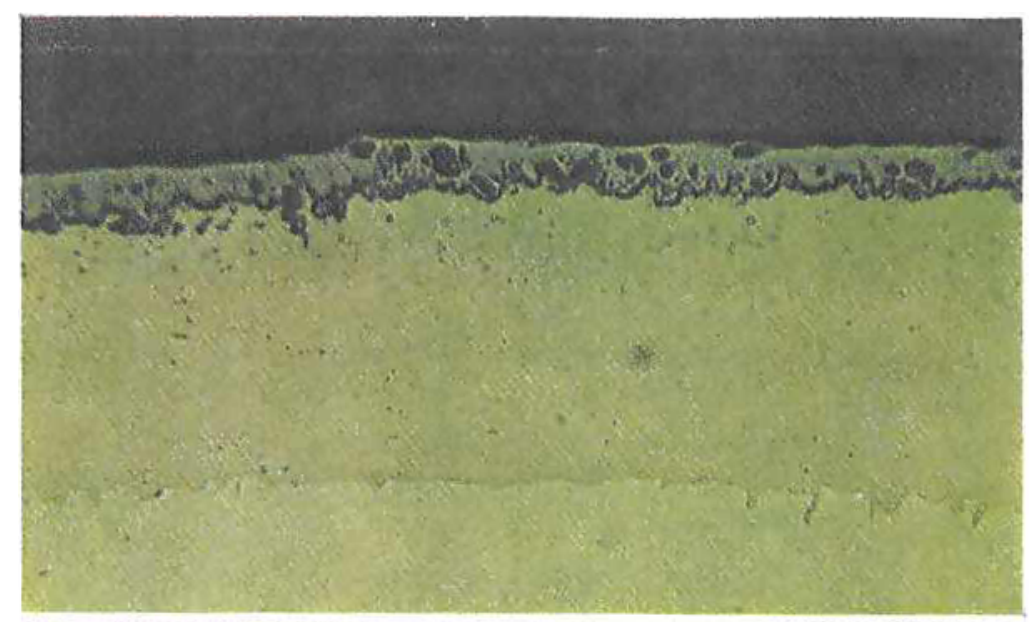

Fig. 4 Gold protection on a chromiumbase alloy after heating to $1000^{\circ} \mathrm{C}$, holding for 20 hours and cooling to room temperature five times. The gold layer is unbroken and still protective

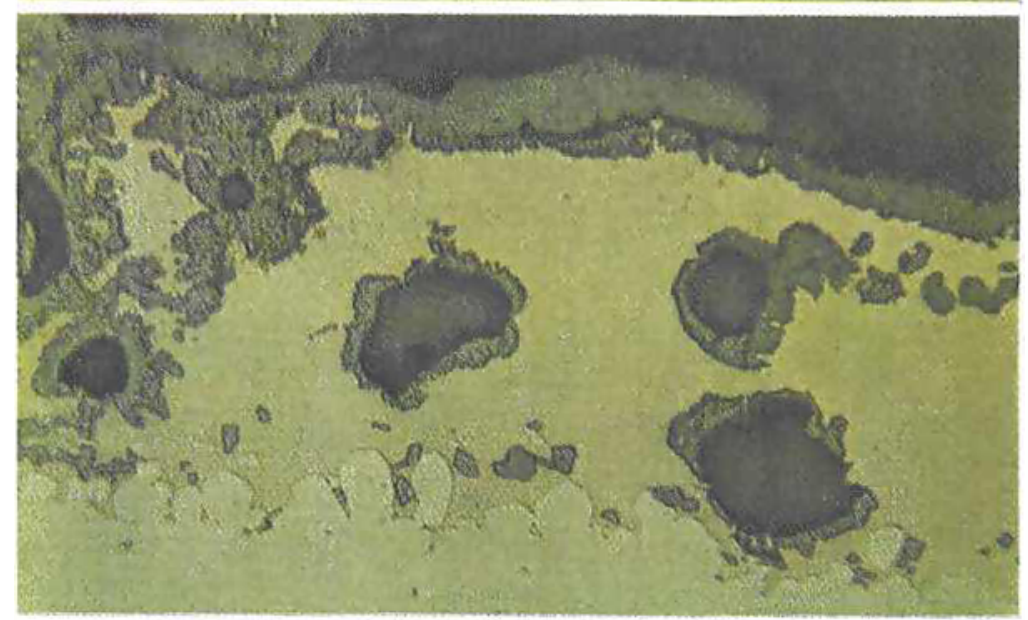

Fig. 5 Gold protection on a chromiumbase alloy after heating to $1100^{\circ} \mathrm{C}$ for 20 hours and cooling to room temperature five times. The gold has melted and attacked the chromium alloy at the grain boundaries $\times \mathbf{3 0 0}$

the transition temperature under both conditions.

The results of such experiments are set out in Tables I and II for pure chromium and for a strong creep-resistant chromium-base alloy. It can be seen that the gold coating has restrained the rise in transition temperature considerably and that the effect is very strong in the high strength alloy.

Table II

The Effect of Gold Protection on the Transition Temperature of a Chromium-Tantalum-Carbon Creep Resistant Alloy

\begin{tabular}{|c|c|c|c|}
\hline \multirow{2}{*}{$\begin{array}{l}\text { Nitridation } \\
\text { Treatment }\end{array}$} & \multicolumn{2}{|c|}{ Transition Temperature ${ }^{\circ} \mathrm{C}$} & \multirow{2}{*}{$\begin{array}{c}\text { Improvement } \\
\text { due to } \\
\text { Coating, }{ }^{\circ} \mathrm{C}\end{array}$} \\
\hline & Unprotected & Gold Coated & \\
\hline $\begin{array}{l}5 \text { cycles of } 20 \text { hours } \\
\text { heating in air at } \\
900^{\circ} \mathrm{C}\end{array}$ & 638 & 337 & 301 \\
\hline $\begin{array}{l}5 \text { cycles of } 20 \text { hours } \\
\text { heating in air at } \\
1000^{\circ} \mathrm{C}\end{array}$ & 487 & 273 & 212 \\
\hline $\begin{array}{l}5 \text { cycles of } 20 \text { hours } \\
\text { heating in air at } \\
1100^{\circ} \mathrm{C}\end{array}$ & 725 & 273 & 450 \\
\hline
\end{tabular}

The fact that there is still protection from nitridation above the melting point of gold is especially striking. The coating would not be used under those conditions because of its lack of erosion resistance and the fact that molten gold penetrates the grain boundaries of chromium. Nevertheless, gold is still effective in preventing nitrogen penetration in static tests. Of course the gold does not melt exactly at its melting point because some chromium enters the gold coating and raises its melting point by about $40^{\circ} \mathrm{C}$.

\section{Upper Temperature Limit}

In practice, it is essential that the gold coating remains solid at the operating temperature. If it melts, not only is it likely to be blown away in the gas stream, but also it penetrates the grain boundaries and individual grains may float in the molten coating. A dramatic illustration of this effect can be seen in the photomicrographs in Figures 4 and 5 . The 
Fig. 6 Chromium-tantalum-carbon alloy Tensomete test pieces with and without gold protection after five cycles in air of heating to $900^{\circ}, 1000^{\circ}$ and $1100^{\circ} \mathrm{C}$ and intermediate rapid cooling to room temperature. The specimens in the upper row were unprotected; those in the lower row were gold plated. The reticulated surface of the gold coating after treatment at $1100^{\circ} \mathrm{C}$ is due to melting of the gold coating. Head diameter $7 \mathrm{~mm}$

coating was pure gold and the chromium alloy contained 2.3 weight per cent tantalum and 0.12 weight per cent carbon. In Figure 4, the coating remained unbroken on cycling to $1000^{\circ} \mathrm{C}$, and did not attack the substrate, while when the heating exceeded the melting point of gold (Figure 5) severe attack took place. The detached grains of chromium alloy can be seen to have floated in the molten coating. This effect, and the appearance of coated and uncoated pieces, are shown in Figure 6. The reticulated coating caused by melting can be seen (lower right). The oxidation and spalled oxides from the bare alloy are clearly seen while the protected pieces, exposed to 900 and $1000^{\circ} \mathrm{C}$, are seen to be in good condition.

\section{Alloy Coatings}

The upper limit of temperature for the use of the gold protection layer can be increased by raising the melting point of the gold coating. This can be achieved by alloying the coating with elements capable of raising the melting point without detracting from the other useful properties of gold. The most appropriate element is palladium.

Palladium forms a continous series of solid solutions with gold as shown in the equilibrium diagram in Figure 7. The solidus temperature is raised to

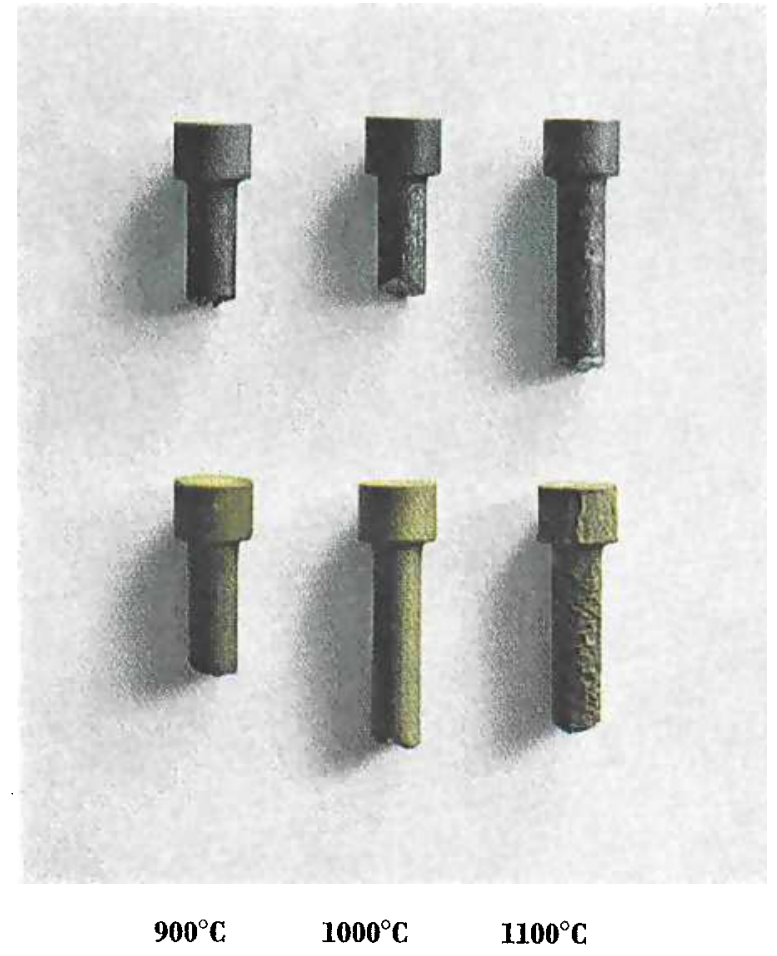

$1150^{\circ} \mathrm{C}$ with 5.7 weight per cent palladium and to $1200^{\circ} \mathrm{C}$ with 8.7 weight per cent. As can be seen from the phase diagram, only small amounts of palladium are needed to achieve a large increase in the melting point.

Although additions of palladium help in increasing the melting point of the coating, it has the effect of encouraging diffusion of chromium from the substrate into the coating and in this way slowly reducing the gold concentration of the coating. The reason for this is the large solubility of chromium in pal-

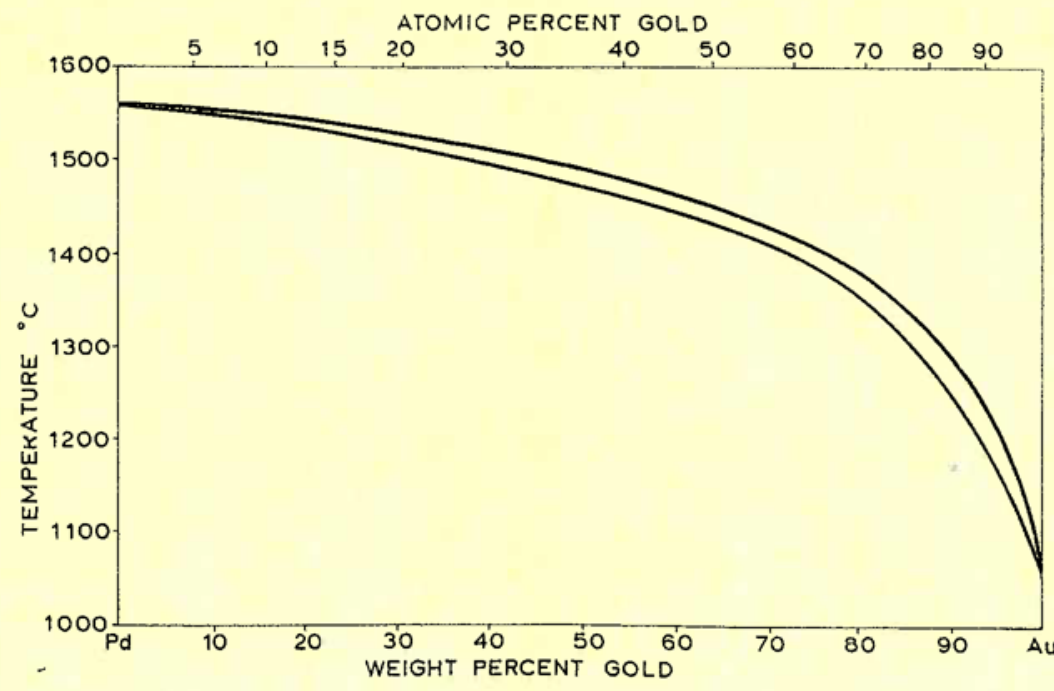

Fig. 7 The gold-palladium equilibrium diagram. For small additions of palladium to gold a useful increase in melting point is obtained and the upper limit of temperature of the protective layer on chromium can thus be increased 
Fig. 8 A gold-10 per cent palladium coating on a chromium-base alloy after vacuum diffusion for 24 hours at $1100^{\circ} \mathrm{C}$, followed by 65 hours in air at $1130{ }^{\circ} \mathrm{C}$. On the outside, chromium oxide has formed from chromium which has diffused through the coating. A line can be seen in the coating which corresponds to the original coating of chromium alloy boundary. Within this line, the coating has extended by diffusion of chromium into the gold alloy

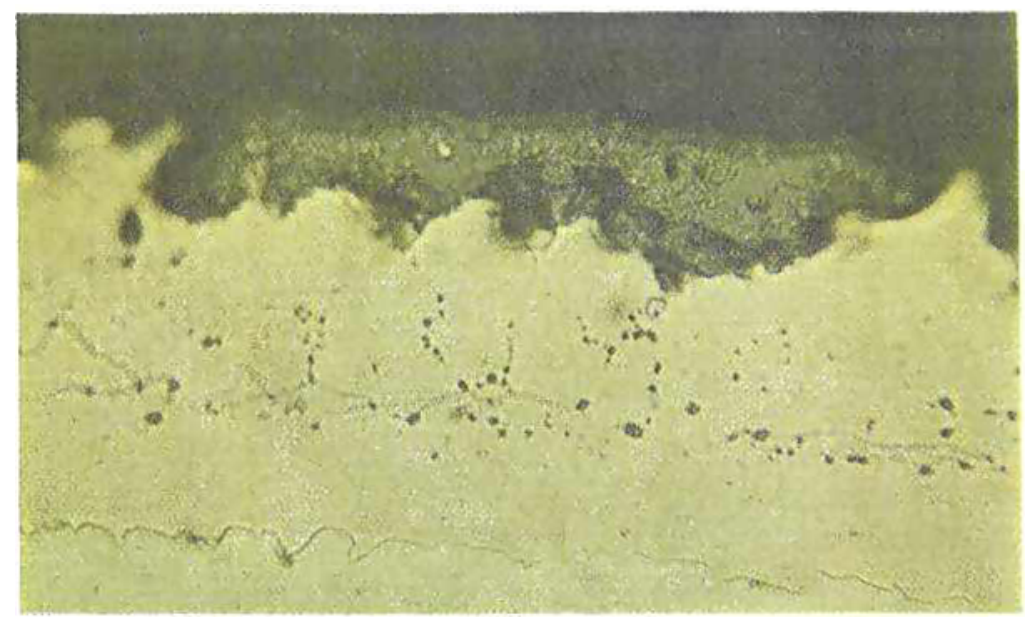

ladium. In practice a palladium layer is plated on top of the gold and is alloyed by heating for 24 hours at $1000^{\circ} \mathrm{C}$ in vacuum. This yields a homogeneous coating of about $30 \mu \mathrm{m}$ thickness. On prolonged heating at $1000^{\circ} \mathrm{C}$ the coating thickness grows as chromium diffuses into the gold-palladium alloy layer because palladium raises the solubility of chromium in gold. However, if this alloy plate is adjusted to give an initial plate composition of gold10 per cent palladium the samples can be cycled five times between room temperature and $1130^{\circ} \mathrm{C}$ and room temperature in air without any loss of the coating or any intercrystalline attack on the substrate.

The condition of this gold-palladium coating after heating, first for 24 hours at $1100^{\circ} \mathrm{C}$ in air, and then for 65 hours at $1130^{\circ} \mathrm{C}$ in air, can be seen in Figure 8 . The line of intermetallic particles in the middle of the coating probably marks the original coating thickness. The coating has spread inwards by dif-

Fig. 9 Gold coating on a chromiumbase alloy after 48 hours at $1100^{\circ} \mathrm{C}$ nominal in a gas turbine simulation rig with 15 intermediate shut-downs. The coating is continuous. Chromium oxide can be seen at the air interface

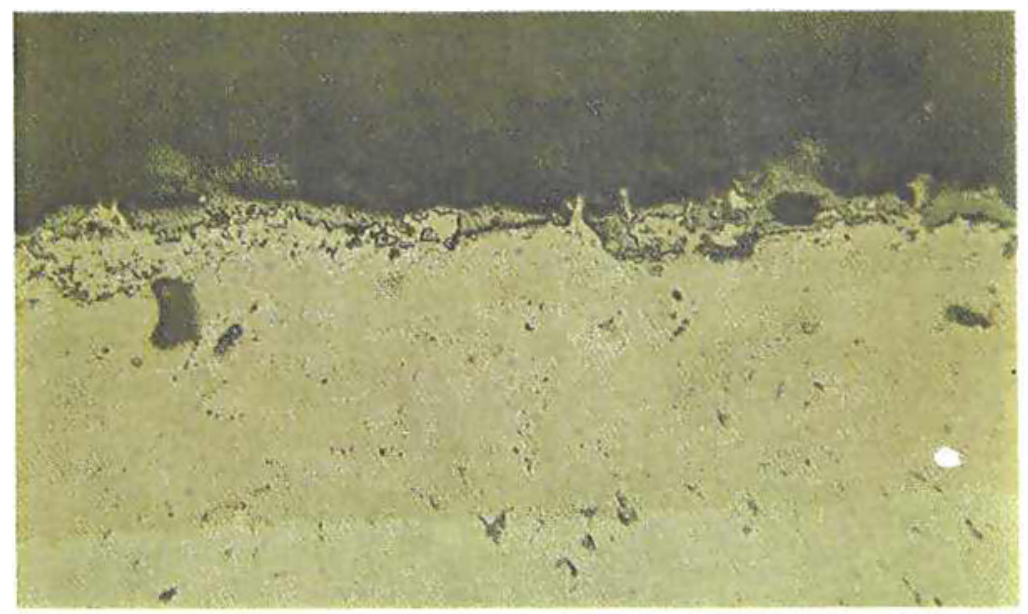

Fig. 10 Gold-palladium on a chromium-base alloy after 48 hours nominal in a gas turbine simulation rig with 15 shut-downs. The boundaries inside the gold alloy coating are probably due to chromium diffusion inte the protective coating. Some chromium oxide forms at the outside surface

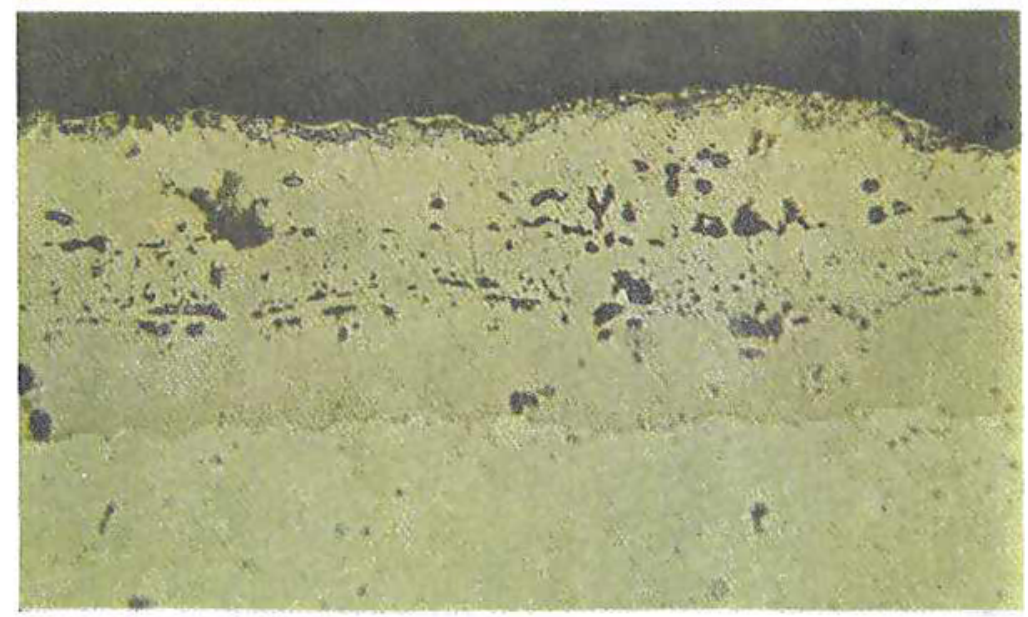


fusion of chromium into the plate. This process is speeded by the presence of the palladium as previously explained. Some chromium diffuses through to the surface where it forms a green oxide. This can be seen in Figure 8 as an outer layer which has become detached from the gold-palladium during the specimen preparation. This thin layer of chromium oxide is no detriment and may be an additional barrier to nitrogen entry.

\section{Gas Turbine Conditions}

A standard test for evaluating the thermal shock resistance of materials for gas turbine engines comprises a spinning rig which rotates bars $85 \mathrm{~mm}$ long, $7.0 \mathrm{~mm}$ diameter, supported in a cage, in and out of a gas jet which cycles the specimen temperature up to $1100^{\circ} \mathrm{C}$, simulating conditions in a gas turbine. A set of chromium alloy bars containing 1 per cent zirconium, 0.2 per cent boron, 1.2 per cent yttrium and 1.0 per cent cerium were coated with gold and gold-palladium in the manner already described.

The coatings all withstood the test, which was carried out at a nominal temperature of $1100^{\circ} \mathrm{C}$ for 48 hours. The coatings were not melted or eroded away, except for a small part of one of the pure gold samples. There were 15 shut-downs during the test run.

Micrographs of the gold-palladium coatings after this test are similar to those in static conditions. Figures 9 and 10 show the coatings at the centre of the bars exposed in the rig. Figure 9 has a gold only coating and Figure 10, a gold +10 per cent palladium coating.
Although it would appear from the unmelted condition of the pure gold coatings that $1100^{\circ} \mathrm{C}$ was not attained, the test was a standard one for simulating gas turbine flame conditions at this nominal temperature. The fact that the coatings have not been eroded or blown off shows that the system is a practical one and merits testing in an actual operating turbine or simulative cascade.

\section{Conclusion}

The nitridation of chromium-base alloys can be considerably retarded by suitably applied gold plating. For temperatures above the melting point of gold, an alloy plate of gold and palladium has been shown to be effective.

Little diffusion of gold into the base metal occurs so that the coating is effective over long periods. Alloying the gold with palladium raises the maximum temperatures to which the coating can be used but also increases diffusion of chromium into the protective layer which therefore slowly increases in thickness. On reaching the outside, the chromium forms a green oxide layer. Considerable reduction in the transition temperature is achieved compared with unprotected chromium or chromium alloys.

Alloys coated by this process withstood gas turbine blade conditions. The development of this protective treatment removes one of the hindrances delaying the use of chromium-base alloys for high strength, high temperature applications.

An application for a patent covering the process described has been made.

\section{Single Crystals of Gold Monochloride}

The monochloride of gold, $\mathrm{AuCl}$, has for long been known as an elusive and transitory substance. Although methods for its preparation have occasionally been given, it is unstable in air and quickly dissociates into its constituent elements. Its crystal structure has therefore never been established. Recently, however, E. M. W. Janssen, J. C. W. Folmer and G. A. Wiegers of the Laboratorium voor Anorganische Chemie at Groningen in the Netherlands have, by studying the thermodynamical data, been successful in preparing quite large single crystals of $\mathrm{AuCl}$, storing them in chlorine at atmospheric pressure in sealed glass tubes at $-20^{\circ} \mathrm{C}$, and measuring their crystal properties ( $F$. Less-Common Metals, 1974, 38, (1), 71-76).

The method of preparation was by vapour transport by way of gaseous $\mathrm{Au}_{2} \mathrm{Cl}_{8}$ in chlorine. First a supply of solid $\mathrm{Au}_{2} \mathrm{Cl}_{6}$ was formed by the reaction of very fine reactive gold powder with chlorine in a quartz tube at $235^{\circ} \mathrm{C}$. The chlorine above the solid in the tube was naturally saturated with gaseous $\mathrm{Au}_{2} \mathrm{Cl}_{6}$, which at this temperature exerted a partial pressure of rather more than 3.8 Torr. The thermodynamic data showed that at a slightly higher temperature the partial pressure of gaseous $\mathrm{Au}_{2} \mathrm{Cl}_{6}$ in chlorine above solid $\mathrm{Au}_{2} \mathrm{Cl}_{6}$ rapidly falls. While, for instance, at $250^{\circ} \mathrm{C}$ it is $3.8 \mathrm{Torr}$, at $280^{\circ} \mathrm{C}$ it is only 2.5 Torr; and the reduction in partial pressure is achieved by deposition of solid $\mathrm{AuCl}$. Accordingly, after forming the solid $\mathrm{Au}_{2} \mathrm{Cl}_{6}$, a temperature gradient of about $25^{\circ} \mathrm{C}$ was set up in the quartz tube, the pressure of chlorine being maintained at one atmosphere. After about a week, half of the $\mathrm{Au}_{2} \mathrm{Cl}_{6}$ solid was transported to the hotter part of the tube, where crystals of $\mathrm{AuCl}$ up to $8 \times 3 \times 3 \mathrm{~mm}$ in size were deposited.

Powder from the crystals was sealed in glass capillaries and examined by $\mathrm{X}$-ray crystallography. $\mathrm{AuCl}$ is shown to be tetragonal, with $a=6.734$ and $c=$ $8.674 \AA$. The structure consists of zig-zag chains of gold and chlorine atoms, with chlorine atoms at the apex points joined to each other by intermediate gold atoms, the interatomic spacing being $2.36 \AA$. The zigzag angle $\mathrm{Au}-\mathrm{Cl}-\mathrm{Au}$ is $92^{\circ}$. The chains run parallel to the $b$ - and $a$-axes.

J. c. C. 